\title{
A educação do campo no contexto da formação continuada de professores
}

Felipe Genaro ${ }^{1}$ Heitor Nascimento Mendes², Marcelo Cervo Chelotti ${ }^{3}$

\begin{abstract}
Resumo
O presente artigo apresenta os resultados obtidos no projeto "Formação continuada de professores de Geografia e sua relação com Educação do Campo no município de Uberlândia-MG", que objetivou inserir a discussão da educação do campo com alunos de cursos de licenciatura da Universidade Federal de Uberlândia (UFU) e professores da rede municipal de ensino, na perspectiva da formação continuada, buscando compreender os limites e as possibilidades de inserção dessa modalidade educacional no município de Uberlândia. Portanto, esses foram os pressupostos que nortearam a construção, bem como a execução do curso no âmbito da UFU.
\end{abstract}

\section{Palavras-chave}

Educação do Campo. Formação de Professores. Questão Agrária.

1. Licenciado em Geografia pela Universidade Federal de Uberlândia, bacharelando em Geografia, bolsista pela Pró-reitoria de Graduação da Universidade Federal de Uberlândia, membro do Laboratório de Geografia Agrária (LAGEA). E-mail: felipegenaro1@hotmail.com.

2. Graduando em Geografia na Universidade Federal de Uberlândia, bolsista pela Pró-reitoria de Graduação da Universidade Federal de Uberlândia, membro do Laboratório de Geografia Agrária (LAGEA).E-mail: heitor1001@ hotmail.com.

3 Doutor em Geografia pela Universidade Federal de Uberlândia, professor nos cursos de graduação e pósgraduação no Instituto de Geografia da Universidade Federal de Uberlândia/MG, membro da Comissão Assessora da Área de Geografia do Instituto Nacional de Estudos e Pesquisas Educacionais Anísio Teixeira (INEP), do Laboratório de Geografia Agrária (LAGEA) e do Núcleo de Estudos Agrários e Territoriais (NEAT-CNPq). E-mail: mcervochelotti@gmail.com. 


\title{
Rural education in the continuing teacher education context
}

Felipe Genaro*, Heitor Nascimento Mendes ${ }^{* *}$, Marcelo Cervo Chelotti***

\begin{abstract}
This article presents the results of the project called "Formação continuada de professores de Geografia e sua relação com Educação do Campo no município de UberlândiaMG" (Continuing education for Geography teachers and their relation with rural education in Uberlândia, Minas Gerais state). This project aimed to provoke a discussion about rural education between bachelor's students at the Federal University of Uberlândia (UFU) and teachers of the municipal system of education, from the continuing education perspective. We have also tried to understand the limits and possibilities of inserting this educational modality in Uberlandia. Therefore, these were the assumptions that have guided the construction, as well as the implementation of the course at UFU.
\end{abstract}

\section{Keywords}

Rural Education. Teacher Education. Agrarian Issue.

\footnotetext{
* Graduated in Geography from the Federal University of Uberlândia, scholar at the Pro-Rectorate of Undergraduate Studies at the Federal University of Uberlândia, member of the Agrarian Geography Laboratory (LAGEA). E-mail: felipegenaro1@hotmail.com.

** Undergraduate student in Geography at the Federal University of Uberlândia, scholar at the Pro-Rectorate of Undergraduate Studies at the Federal University of Uberlândia, member of the Agrarian Geography Laboratory (LAGEA). E-mail: heitor1001@hotmail.com.

*** Doctor in Geography from the Federal University of Uberlândia, professor in undergraduate and postgraduate courses at the Institute of Geography at the Federal University of Uberlândia, member of Advisory Committee of Geography of the National Institute of Studies and Educational Research Anisio Teixeira (INEP), at the Agrarian Geography Laboratory (LAGEA), and Agrarian and Territorial Studies Center (NEAT-CNPq). E-mail: mcervochelotti@ gmail.com.
} 


\section{Introdução}

Nas últimas décadas, foi intenso o processo de transformação no espaço agrário de Uberlândia-MG, na medida em que o município se constituía como um grande polo agroindustrial do centro-sul do Brasil. Contraditoriamente, é nesse território quetambém, nasúltimas décadas, evidenciam-se intensos conflitos fundiários associados à atuação de movimentos sociais de luta por terra. Atualmente, existem quinze assentamentos rurais com aproximadamente 832 famílias. Esse fato explicita as necessidades de se pensar uma educação que atenda as necessidades educacionais dessas pessoas.

Dentro dessa condicionante, uma das formas de solucionar esse déficit educacional das famílias nos assentamentos está vinculada à formação do professor. É por meio dessa formação que o professor será capaz de contextualizar o conteúdo com a realidade agrária, buscando romper com os preconceitos existentes, inclusive entre os próprios alunos, e visando sanar as dificuldades de aprendizado, muitas vezes resultante da incapacidade do professor de buscar melhores formas de lidar com a realidade desses alunos. Esse professor deve, então, buscar uma formação continuada que Ihe propicie entender a realidade agrária do Brasil, e, por consequência, o contexto vivido por seus alunos.

Diante dessas problemáticas, o projeto "Formação continuada de professores de Geografia e sua relação com Educação do Campo no município de Uberlândia-MG", financiado pela Pró-reitoria de Graduação da Universidade Federal de Uberlândia (PROGRAD/UFU), teve como objetivo principal capacitar professores da rede municipal de ensino de Uberlândia - atuantes em escolas que atendem alunos provenientes de assentamentos rurais de reforma agrária -, alunos dos cursos de licenciatura da UFU e demais interessados no tema, proporcionando-Ihes uma maior aproximação às necessidades da Educação do Campo no país e, principalmente, no município de Uberlândia.

Para essa formação, como objetivos específicos que a proporcionaram, discutiu-se a interface entre Educação do Campo e Educação Geográfica; buscou-se identificar os limites e possibilidades de inserção da Educação do Campo no município de Uberlândia, inserir o futuro licenciado em Geografia no âmbito da pesquisa, com interface no ensino e na extensão, voltada às práticas educacionais associadas à Educação do Campo, além de aproximar a UFU, enquanto instituição pública, da realidade socioespacial encontrada em seu entorno.

\section{Procedimentos metodológicos}

Para realização do projeto, a metodologia foi dividida em duas etapas: teórica e prática. A etapa teórica constituiu na realização de um levantamento bibliográfico sobre a diferenciação da Educação Rural e da Educação do Campo. Em um segundo momento, analisou-se o decreto 7.352, identificando as orientações gerais sobre a nova política de Educação do Campo. Posteriormente, estabeleceram-se as possíveis interlocuções entre a Educação do Campo e a Educação Geográfica, além do levantamento de dados referentes ao número de público potencial para a Educação do Campo no município de Uberlândia.

A etapa prática ocorreu a partir do diagnóstico realizado a priori e da elaboração de metodologias adequadas à Educação do Campo em ambiente de assentamentos rurais, seguidos da realização de um curso de formação continuada em forma de evento (40 horas/aula) para professores que atuam na rede municipal de ensino e que trabalham com alunos provenientes de assentamentos rurais, assim como os demais interessados no tema. $\mathrm{O}$ presente artigo visa apresentar os resultados desse curso, a última parte da etapa prática do projeto. 
O curso foi realizado no Campus Santa Mônica da Universidade Federal de Uberlândia, entre os dias 5 a 10 de agosto de 2013. Foram cinquenta inscritos para os seis dias de evento. Buscou-se trabalhar, em cada dia, diferentes temáticas relacionadas à realidade do campo no Brasil, como a modernização da agricultura, os desafios da formação continuada etc., sendo possível uma abordagem mais ampla da atualidade rural do município de Uberlândia. Durante os seis dias de curso, foram propostas diferentes discussões de temas pertinentes à Educação do Campo. O quadro 1 apresenta a programação do curso e os temas discutidos em cada dia.

Quadro 1 - Programação do curso.

\begin{tabular}{|c|c|c|c|c|c|}
\hline $\begin{array}{c}\text { Segunda } \\
05 / 08\end{array}$ & $\begin{array}{l}\text { Terça } \\
\text { 06/08 }\end{array}$ & $\begin{array}{l}\text { Quarta } \\
07 / 08\end{array}$ & $\begin{array}{l}\text { Quinta } \\
08 / 08\end{array}$ & $\begin{array}{l}\text { Sexta } \\
09 / 08\end{array}$ & $\begin{array}{c}\text { Sábado } \\
\text { 10/08 }\end{array}$ \\
\hline $\begin{array}{c}14 \mathrm{~h} \\
\text { Apresentação } \\
\text { do curso } \\
15 \mathrm{~h} \text { às } 18 \mathrm{~h} \\
\text { Os desafios } \\
\text { da formação } \\
\text { continuada } \\
\text { de professores }\end{array}$ & $\begin{array}{c}14 \mathrm{~h} \text { às } 18 \mathrm{~h} \\
\text { A } \\
\text { modernização } \\
\text { da agricultura } \\
\text { e seus efeitos } \\
\text { sociais e } \\
\text { ambientais }\end{array}$ & $\begin{array}{c}\text { 14h às } 18 \mathrm{~h} \\
\text { Movimentos } \\
\text { sociais e } \\
\text { educação: } \\
\text { o setor de } \\
\text { educação do } \\
\text { MST }\end{array}$ & $\begin{array}{c}\text { 14h às } 16 \mathrm{~h} \\
\text { A geografia } \\
\text { da luta pela } \\
\text { terra em } \\
\text { Minas Gerais } \\
16 \mathrm{~h} 15 \\
\text { às } 18 \mathrm{~h} \\
\text { Memórias } \\
\text { da luta pela } \\
\text { educação } \\
\text { e pela terra } \\
\text { no Triângulo } \\
\text { Mineiro }\end{array}$ & $\begin{array}{l}\text { 14h às } 16 \mathrm{~h} \\
\text { Interlocução } \\
\text { entre a } \\
\text { Geografia e a } \\
\text { Educação do } \\
\text { Campo } \\
16 \text { h15 às } \\
18 \mathrm{~h} \text { Projeto } \\
\text { de extensão } \\
\text { A Geografia } \\
\text { vai ao } \\
\text { acampamento }\end{array}$ & $\begin{array}{c}9 \mathrm{~h} \\
\text { Trabalho } \\
\text { de campo: } \\
\text { acampamento } \\
\text { 10 de Maio e } \\
\text { assentamento } \\
\text { Emiliano } \\
\text { Zapata (MST) }\end{array}$ \\
\hline
\end{tabular}

Fonte: Os autores (2013).

\section{0 município de Uberlândia: um campo de contrastes}

A incorporação da agricultura moderna no Cerrado Mineiro inicia-se a partir da década de 1970, com os "Planos Nacionais de Desenvolvimento", protagonizados pelos militares e acordados com o capital internacional. O governo, em parceria com a iniciativa privada, promoveu a adoção do modelo de produção agrícola estadunidense, provindo da Revolução Verde.

ARevolução Verde, segundo Delgado(1985), refere-se à introdução de novas tecnologias aplicadas à agricultura, principalmente no período pós Segunda Guerra. Esse modelo consistia em um pacote tecnológico que implicou transformações como: adaptação das inovações biológicas às estratégias industriais das inovações mecânicas e fisioquímicas; estreita vinculação da adoção tecnológica à política de crédito rural e aos serviços de assistência técnica governamental; inovações em geral apoiadas numa matriz energética intensiva no uso de derivados do petróleo. A introdução desse modelo de produção no Cerrado Mineiro promoveu transformações não apenas de cunho econômico, mas também sociais. A região, e por consequência o município de Uberlândia, beneficiou-se com os 
planos de modernização da agricultura. A sua posição estratégica no território, a infraestrutura de transporte existente e o capital concentrado na região contribuíram para que a região fosse uma das primeiras no país a incorporar os modelos agroindustriais no seu meio produtivo.

Essas condições favoráveis ao desenvolvimento econômico promoveram uma atratividade migratória para a mesorregião. De acordo com Pessôa (2007), incentivados pelo governo e atraídos pelo alto rendimento da produção de café, produtores do Paraná e de São Paulo vieram para a região, fugindo das geadas que destruíam produções inteiras no sul. Outros migrantes, vindos majoritariamente do Rio Grande do Sul, buscaram a região para produzir soja. Apesar de apresentar grande rentabilidade, a produção nas áreas de Cerrado dependia de grandes investimentos em insumos. Vários produtores que chegavam à região não tinham recursos para produzir ou, muitas vezes, não conseguiam nem acesso a terra.

A agricultura moderna, expressa no agronegócio que se expandiu no Cerrado, pautou-se por ações políticas estrategicamente elaboradas por um seleto grupo de agentes da economia, que introduziram no território as inovações técnico-científicas que permitiram viabilizar a produção, priorizando o benefício dos grandes produtores e excluindo os pequenos produtores familiares. A subordinação da produção ao capital tornava-se mais intensa na medida em que o modelo agroindustrial avançava:

É o caráter social e irreversível da industrialização da agricultura que permite a criação de um verdadeiro proletariado rural, estreitando-se a possibilidade de reprodução de formas independentes da pequena produção ou de formas em que o trabalhador mantém o controle do processo do trabalho. Em outras palavras, a industrialização da agricultura determina a passagem da subordinação indireta para a subordinação direta do trabalho ao capital. (SILVA, 1996, p. 34).

Os pequenos agricultores, excluídos do processo de modernização, ficaram fadados a servirem de mão-de-obra em grandes latifúndios ou na cidade. Alguns não encontravam mais o sustento na terra e se viram forçados a arrendar ou vender as suas para os grandes latifundiários. Frente à exclusão social, esta parcela de pequenos agricultores, somada aos migrantes sulistas, buscou, a partir da década de 1980, organizar-se em movimentos sociais.

Os primeiros movimentos "sem-terra" da região começaram a se organizar por volta de 1983, por intermédio da Comissão Pastoral da Terra (CPT). A CPT, por vezes, fazia a ligação dos manifestantes locais com o Movimento dos Trabalhadores Sem-Terra (MST), que já se configurava como o movimento de luta pela terra de maior força política no país. O final da década de 1980 e a primeira metade da década seguinte foram marcados por diversas ocupações e conflitos entre manifestantes e latifundiários. A grande violência dos conflitos e as poucas conquistas do período fizeram com que o MST perdesse a credibilidade frente aos outros manifestantes. Com o enfraquecimento do MST, surgem outros movimentos de luta pela terra como o Movimento Democrático dos Sem Terra (MDST), que dá origem ao Movimento de Luta pela Terra (MLT), e o Movimento de Libertação dos Sem Terra (MLST de Luta), movimento regional que, em 2000, rompe com a direção nacional do MLST, dentre outros.

Segundo os dados fornecidos pelo relatório de 2010 do Banco de Dados da Luta Pela Terra (DATALUTA MG), de 1990 a 2010, o município de Uberlândia apresenta o maior número de ocupações do Estado (50 ocupações) e o maior número de famílias atuando nessas ocupações (7495 famílias). O primeiro assentamento conquistado por um movimento de luta pela 
terra foi o Assentamento Rio das Pedras, em 1998 (DATALUTA MG, 2010). A ocupação da fazenda foi realizada no ano 1997, liderada pelo
MLST de Luta. Atualmente, em Uberlândia, há 15 assentamentos (Mapa 1), onde residem 832 famílias.

Mapa 1 - Localização Projetos de Assentamentos no município de Uberlândia - MG.
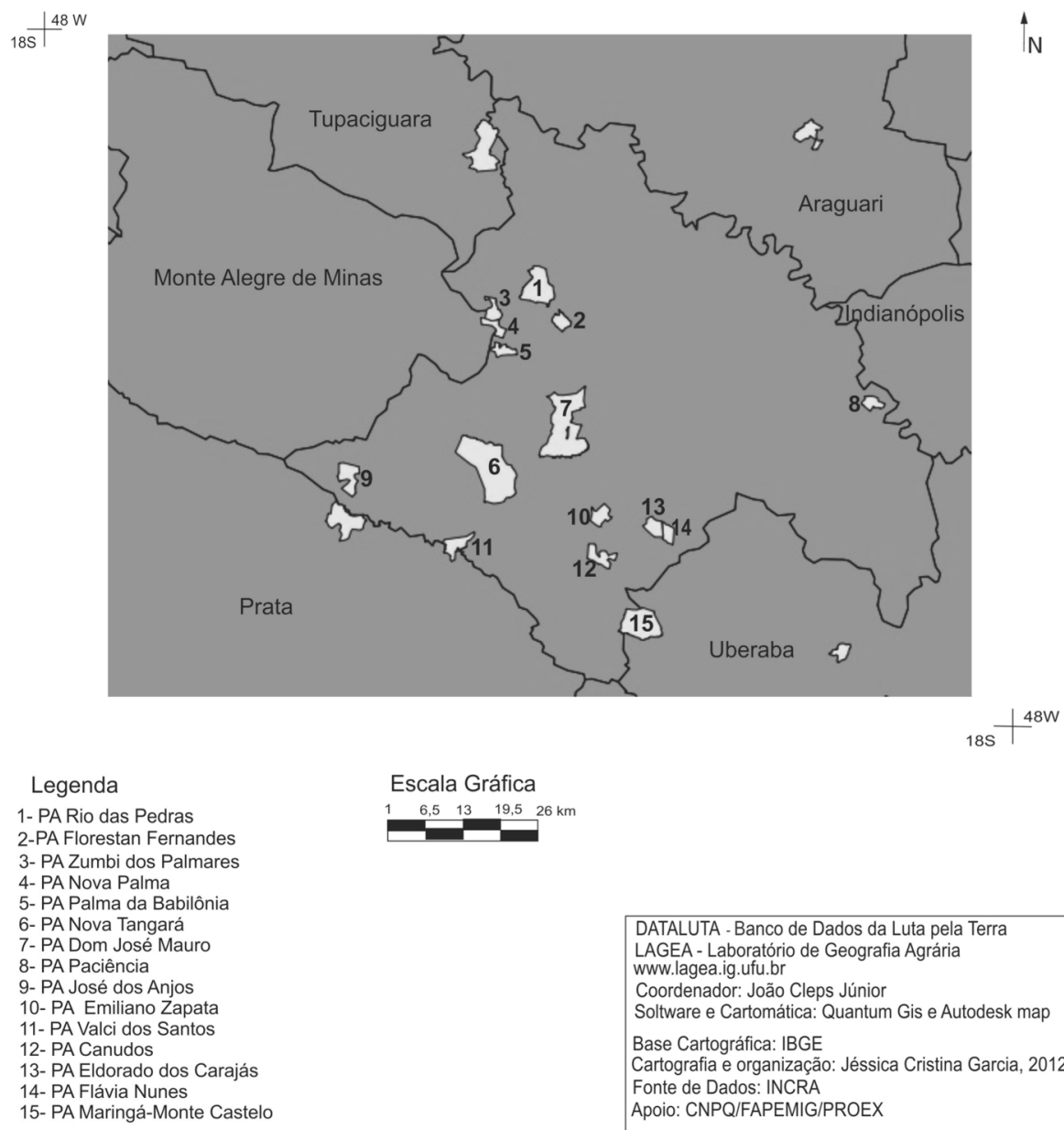

DATALUTA - Banco de Dados da Luta pela Terra LAGEA - Laboratório de Geografia Agrária

Co.lagea.ig.utu.br

João Cleps Júnior

Soltware e Cartomática: Quantum Gis e Autodesk map

Base Cartográfica: IBGE

Cartografia e organização: Jéssica Cristina Garcia, 2012

Fonte de Dados: INCRA

Apoio: CNPQ/FAPEMIG/PROEX

Fonte: DATALUTA, MG (2010).

\section{Contextualizando a educação do campo}

A partir do Decreto 7.352, de 4 de novembro de 2010, a Educação do Campo ganha destaque na esfera das políticas públicas, atendendo a uma demanda dos movimentos sociais do campo e resgatando uma dívida histórica do Estado brasileiro com camponeses e camponesas de todo território nacional. O Decreto entende como Educação do Campo: as populações do campo - agricultores familiares, extrativistas, pescadores artesanais, ribeirinhos, assentados e acampados da reforma agrária, trabalhadores assalariados rurais, quilombolas, caiçaras, povos 
da floresta, caboclos e outros que produzam suas condições materiais de existência a partir do trabalho no meio rural - e a escola do campo, aquelas situadas em área rural, conforme definida pelo Instituto Brasileiro de Geografia e Estatística - IBGE, ou aquelas situadas em área urbana, desde que atendam predominantemente as populações do campo.

Werthein e Bordevane (1985) salientam que, na educação rural, devem ser consideradas características socioeconômicas e culturais, para se elaborar qualquer estratégia educacional que possa dar respaldo às necessidades e interesses de tal população. No Brasil, os projetos relacionados à educação rural tiveram como objetivos principais controlar a população camponesa, visando evitar o abandono do campo e a migração para cidade ou propiciar uma educação técnica para criar mão-de-obra a favor da modernização da agricultura. Esse processo pode ser verificado ainda na República Velha, quando as atenções voltaram-se para educação rural como forma de se evitar a forte corrente migratória dos camponeses para as cidades. Concomitante, conforme assinalado por Leite (2002, p. 28-29),

[...] explodia a ideologia do colonialismo que, ao defender as virtudes do campo e da vida campesina mascarava sua preocupação maior: esvaziamento populacional das áreas rurais, enfraquecimento social e político do patriarcalismo e forte oposição ao movimento progressista urbano, isso principalmente por parte dos agroexportadores, mas o ruralismo contou também com o apoio de alguns segmentos das elites urbanas, que viam na fixação do homem no campo uma maneira de evitar a exploração de problemas sociais nos centros citados.

Também pode ser analisada a criação da Companhia Nacional de Educação Rural (CNER) na década de 1950, que, na realidade, foi apenas um mecanismo do Estado para controlar a economia por meio da modernização da agricultura nos modelos indicados pelos EUA, como já havia ocorrido com a Associação de Crédito e Assistência Rural da Empresa Brasileira de Extensão Rural (ACAR/EMATER).

Centrada na ideologia do desenvolvimento comunitário, a modernização do campo nada mais foi do que a internacionalização da economia brasileira aos interesses monopolistas, e a CNER, ao realizar seu trabalho educativo, desconsiderou as contradições naturais dos grupos campesinos, ou mesmo seus elementos integrativos, quer políticos, sociais ou culturais. Além disso, as lutas ou reivindicações rurais ficaram obscurecidas, sucumbido frente às expressões comunitárias repassadas pela educação/ informação veiculadas na campanha. (LEITE, 2002, p. 37).

Em relação à regulamentação da educação no país, destacam-se: a Lei de Diretrizes e Bases (LDB), de 1961, que deixou a educação rural sob os cuidados de municípios falidos e descapacitados; a Lei 5.692, de 1971, que apenas regulamentou a criação da oitava série e a ampliação do ensino técnico; e a atual LDB, Lei 9.394, criada em 1996, que se destaca por conter, em seu Art. 28, adaptações necessárias para adequação da educação às singularidades da população rural, destacando:

I - Conteúdos curriculares e metodologias apropriadas às reais necessidades e interesses dos alunos da zona rural; II - Organização escolar própria, incluindo a adequação do calendário escolar às fases do ciclo agrícola e às condições climáticas; III - Adequação à natureza do trabalho na zona rural. (BRASIL, 1996).

A LDB de 1996 é um avanço do III Plano Setorial da Educação, Cultura e Desporto (1980-1985), porém não está sendo cumprida, principalmente pela falta de recursos destinados à educação e pelo pouco comprometimento dos Governos com a população camponesa. 
Na visão de Brandão (2005), os conteúdos do Art. 28 da LDB/9.394 não estão sendo efetivamente aplicados na realidade educacional brasileira por dois motivos: o êxodo rural e o transporte de grande parte dos alunos da zona rural para as escolas na zona urbana.

Tendo em vista os problemas históricos da educação no campo e a dificuldade de inserir a população camponesa na educação urbana convencional, o MST cria, em 1997, a primeira Escola Itinerante no Rio Grande do Sul, destacando, entre os principais motivos da luta por essa escola:

A dificuldade de acesso à escola convencional por estarem acampados em áreas rurais geralmente longe das instituições educativas formais, e também o questionamento da função social da escola convencional que historicamente tem estado descomprometida com as questões referentes às desigualdades sociais, econômicas e culturais, e, portanto, desvinculada do projeto Sem Terra. (MEURER; DE DAVID, 2008, p. 46).

A criação da Escola Itinerante foi motivada, principalmente, pelas reivindicações das famílias e professores preocupados com o futuro das crianças nos acampamentos, que enfrentavam problemas para chegar até as escolas, geralmente situadas longe da área rural onde residiam, além do preconceito por parte de colegas e professores em relação à ideologia de seus pais, que, por estarem em constante deslocamento, não conseguiam matriculá-las nas escolas convencionais. Para Pulh e Meurer (2009), a Universidade, principalmente por meio de seus cursos de licenciatura, devem efetivar práticas comprometidas, por meio de vivências e debates com as instituições alternativas, e ampliar a perspectiva da formação dos educadores. Nesse contexto, a Escola Itinerante do MST emerge como uma proposta diferenciada de ensino, cuja prática compreende um olhar crítico sobre a sociedade e os meios de dominação/exclusão impostos à comunidade acampada, da qual fazem parte seus educandos e educadores.

[...] Neste sentido, projetos integrados entre os cursos de licenciatura, como é o caso do projeto integrado com professores e alunos da escola itinerante envolvendo os cursos de pedagogia e geografia da UFSM, são importantes para que os profissionais da educação em formação possam ter uma compreensão da realidade em que trabalham. Além disso, permitem compreender as consequências que suas práticas têm sobre os alunos e sobre a comunidade escolar com os quais se envolvem. (MEURER; DAVID, 2008, p. 51-52).

Nesse contexto, o Triângulo Mineiro configura-se como um lócus ideal para se discutir os desafios e as perspectivas da Educação do Campo, uma vez que, nas últimas décadas, foi intenso o processo de transformação em seu espaço agrário, na medida em que se tornou um grande polo agroindustrial associado ao agronegócio agroexportador. Contraditoriamente, é nesse território que, também nas últimas décadas, evidenciaram-se intensos conflitos fundiários, associados à atuação dos movimentos sociais, que se territorializaram por meio da conquista de dezenas de assentamentos rurais em vários municípios da região. Assim, insere-se a necessidade da formação continuada de professores que atuam nessas áreas, para que esses profissionais possam ser capazes de contextualizar o conteúdo com a realidade rural, buscando romper com os preconceitos e visando sanar as dificuldades de aprendizado atribuídas a um processo de reterritorialização. 


\section{A educação do campo como formação continuada: 0 curso de extensão}

O curso de extensão "Contribuições da Geografia Agrária com a Educação do Campo" aconteceu no mês de agosto, no Campus Santa Mônica, na Universidade Federal de Uberlândia e contou com a presença de alguns representantes de movimentos sociais de luta pela terra do município - respaldando ainda mais uma discussão que é inerente à vida dessas pessoas e que pode contribuir para o entendimento das reais necessidades da formação do professor que trabalha ou trabalhará com a educação do campo - além de várias palestras, perfazendo a carga horária de 40 horas, ministradas por professores e acadêmicos do Instituto de Geografia que trabalham com educação do campo e formação continuada de professores (Imagem 1).

Imagem 1 - Cartaz de divulgação do curso de extensão "Contribuições da Geografia Agrária com a Educação do Campo".

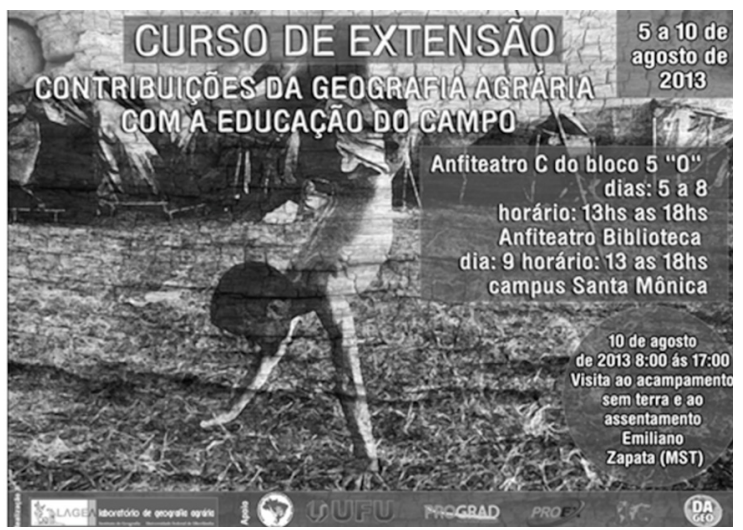

Fonte: Os autores.

O primeiro debate realizado discorreu sobre a importância da formação continuada de professores, os desafios na carreira de licenciatura e a necessidade constante do professor buscar complementar sua formação para atender às diferentes necessidades apresentadas pelos alunos. Após essa primeira discussão, foram abordadas questões referentes à modernização da agricultura e seus efeitos sociais, como o êxodo rural e a concentração fundiária. A compreensão dessa temática pode auxiliar o cursando a entender as formas de resistência a esse modelo produtivo, que gera um cenário de desigualdade no campo brasileiro. Nessa fase, o curso trabalhou a gênese dos movimentos sociais de luta pela terra, em escala nacional, estadual e regional, e como esses movimentos "espacializam-se" na forma de assentamentos e acampamentos na região do Triângulo Mineiro.

A partir dessa base, foram trabalhadas questões educacionais que se manifestam no complicado cenário da luta pela terra. Foram apresentadas as questões teóricas referentes à Educação do Campo, assim como os modelos pedagógicos adotados pelos movimentos sociais. O objetivo, neste momento do curso, foi traçar um paralelo entre a deficiência do modelo educacional comum em contemplar a realidade do povo do campo e a necessidade da busca por uma educação emancipadora que supere esta deficiência.

$\mathrm{O}$ passo seguinte foi trabalhar a interlocução entre a Geografia e a Educação do Campo, buscando tecer as formas com que a ciência geográfica pode contribuir para a consolidação desse modelo educacional, principalmente no debate de como as questões socioterritoriais influem na educação. Após a apresentação teórica, o debate foi ilustrado com a apresentação de alguns projetos de extensão realizados pelo Laboratório de Geografia Agrária (LAGEA), que levaram as questões teóricas acerca da temática para acampamentos e assentamentos.

Ao final do curso, foi proposto um trabalho de campo voltado para um acampamento e um assentamento da região, a fim de levar os participantes a conhecerem a realidade debatida em sala de aula e, por meio do conhecimento empírico, reforçar o que se aprendeu durante o curso. 
A todos os cursistas foi aplicado um questionário para que indicassem suas perspectivas em relação ao curso. As respostas apontaram perspectivas variadas, tendo em vista os participantes serem estudantes de cursos de graduação diversos (Agronomia, Letras, Geografia e História). Entende-se que essas diferentes vertentes, de alguma forma, podem ampliar as condições para lidar com a realidade do campo brasileiro. O Quadro 2 apresenta algumas das diferentes intenções de participação no curso, evidenciando a transversalidade do tema e a importância de sua abordagem interdisciplinar.

Quadro 2 - O que o motiva a participar do curso?

\begin{tabular}{ll}
\hline C1 "Ter maior compreensão sobre as contribuições da Geografia Agrária com a educação do \\
campo, bem como os diálogos da Geografia com os movimentos sociais de luta pela terra". \\
"Comoaluna participantedoPIBID, edosubprojetoeducaçãonocampo,émuitointeressante \\
queeufaçaessecurso,alémdomeugrandeinteresseemfazerpós-graduaçãoemassuntosafins". \\
"Oportunidade de uma melhor capacitação para o mercado de trabalho". \\
C4 "A temática do curso se torna motivadora, uma vez que vem complementar o conteúdo \\
desenvolvido em âmbito acadêmico. Cursos como este são de crucial importância para \\
a carreira docente, sendo que abre margens para novos conhecimentos em relação à \\
Educação no Campo. Como por exemplo, em relação à modernização da agricultura \\
e suas respectivas implicações, a educação do campo oferecida pelos próprios \\
movimentos sociais, a relação da geografia com os processos educacionais no campo, \\
dentre outros. Enfim, tal curso contribuirá para a formação docente, assim como \\
também auxiliará na atuação como professor se possível também em ambientes rurais". \\
"Conhecer os movimentos e como eles são estudados e ensinados no contexto da Reforma \\
Agrária e do MST". \\
"O que me motiva a participar do curso é o tema da minha monografia, que envolve \\
educação do campo". \\
"Atuante na área de Educação do Campo". \\
"Sou interessado em conhecer e estudar os movimentos sociais no Brasil, como os \\
movimentos por moradia, e pela reforma agrária. Além disso, já tive outras oportunidades \\
de visitar áreas ocupadas - acampamentos dos Sem-Terra e assentamentos - sendo este \\
curso ótimo para aprofundar teoricamente e na prática, o cotidiano de trabalho e luta dos \\
camponeses". \\
"Pelas discussões propostas no curso e uma aproximação com a temática da Educação do \\
Campo". \\
C10
\end{tabular}

Fonte: Os autores. 
No último dia, realizou-se a avaliação entre os cursistas. O Quadro 3 demonstra que o curso foi considerado bastante proveitoso pela grande maioria, satisfazendo as perspectivas. As críticas foram bastante construtivas e ajudaram na análise dos objetivos propostos e sua real importância para os participantes. O quadro 4 apresenta algumas dessas críticas e sugestões expostas pelo grupo, seguido dos gráficos, aplicabilidade e formas de apresentação dos módulos, que são resultado de um questionário fechado, no qual cada uma analisava entre ótimo, bom, regular ou ruim, esses dois quesitos.

Quadro 3: Em sua opinião, qual a importância dos estudos referentes à educação do campo?

C1 "Como participo do PIBID - Educação do Campo, é fundamental conhecer diferentes trabalhos de pessoas que estão a mais tempo estudando a educação do campo, a partir dos mesmos. Pode-se perceber como é importante o conhecimento sobre o mesmo, já que o que é mais estudado, implantado, é a educação urbana; a educação do campo fica esquecida".

C2 "É muito importante para trazer as discussões a respeito dos vários aspectos que foram levantados durante o curso e que não temos tanto contato".

C3 "Esse tipo de estudo se torna importante para avaliação da situação não só na educação, mas em todas as áreas e situações vivenciadas no campo".

C4 "Em conhecer o que de fato é ou se existe educação do campo. Entender a lógica da modernização da agricultura e quais fatores interferem na vida das pessoas residentes naqueles ambientes. Conhecer e desmistificar o que a mídia apresenta sobre a luta do MST e dos outros movimentos que lutam pelos direitos a terra e por uma reforma agrária popular".

C5 "São extremamente importantes, visto que a população do campo é a que mais sofre pela ausência de políticas públicas afirmativas da justiça social e pela ausência de uma educação libertadora".

C6 "Em uma época praticamente dominada pelo agronegócio e pelas transnacionais, garantir uma educação de qualidade é fundamental à população do campo para que esta saiba lutar pelos seus direitos e estabelecer condições de vida dignas. Para isso, são necessárias estudos da educação do campo; conhecer os povos que constituem essas comunidades, suas dificuldades, as relações sociais que elas travam etc".

C7 "Em minha opinião, a educação no/do campo é um instrumento importantíssimo para a articulação das relações sociais de produção que ali ocorrem, e podem, dependendo de como e quem a utiliza, abrir novas possibilidades de articulação para aqueles que vivem sua realidade cotidianamente".

C8 "Como professora do ensino básico, acredito que discutir a educação do campo é importante não apenas para minha formação e atuação profissional, mas também para desenvolver uma consciência crítica a respeito do modelo educacional urbano imposto".

C9 "A educação do campo é importante, pois é necessário valorizar a realidade e o cotidiano dos indivíduos que habitam e trabalham no campo".

C10 "Vi uma realidade por um ponto de vista diferente, já que sou graduando em agronomia, e isto me fez refletir sobre isso".

Fonte: Os autores. 
Quadro 4: Sugestões, críticas e comentários sobre o curso de extensão.

C1 "O curso foi enriquecedor, pois além de abranger uma ampla teoria, também abrangeu a prática".

C2 "O curso foi muito útil e de muito aprendizado sobre o assunto, pois estavam presentes pessoas que retrataram a realidade da educação e que estão dispostas a defender a melhoria dessa. Foi útil também para a minha realidade profissional, que ainda era muito crua em relação ao assunto tratado".

C3 "Não possuo críticas relevantes sobre o curso. No geral, fiquei bastante satisfeita com os conteúdos ministrados".

C4 "Curso muito interessante, pois houve discussões sobre a dinâmica do espaço rural ou agrícola no território, fazendo ligações do agronegócio com a educação no campo. De modo geral o curso foi bem estruturado e pensado, trazendo pesquisadores que são referência nos estudos da modernização do campo, bem como pessoas que vivem e trabalham com educação no campo'.

C5 "Curso muito interessante, visto que na Agronomia esse assunto não é debatido desta forma".

C6 "Particularmente, o curso foi bem satisfatório, pois me deu conhecimento didático e de vivência, podendo entender, assim, a realidade do ensino no campo".

C7 "O curso foi muito válido para ampliar a visão que o licenciado em Geografia tem sobre as diversas formas que a educação assume".

C8 "Achei o curso extremamente proveitoso e construtivo. Sugiro para os próximos a busca de apresentadores/debatedores relacionados a outras áreas e enfoques relacionados à questão agrária, para enriquecimento dos debates. Sugiro também momentos de mesaredonda, onde a facilitador seria tão sujeito da construção do conhecimento quanto o público".

C9 "De modo geral achei o curso proveitoso. No entanto senti falta de atividades mais interativas com os participantes".

C10 "Faltou a visão do latifundiário, para termos o outro lado da moeda".

Fonte: Os autores.

Portanto, os estudos referentes à formação de futuros profissionais da educação, Educação do Campo propiciaram aos futuros professores a compreensão da forma com que as questões socioterritoriais influenciam no processo de ensino e aprendizagem e os capacitam a desenvolver uma didática de ensino capaz de atender a realidade de seus alunos. Apesar desta grande contribuição na a temática ainda é pouco trabalhada nos cursos de licenciatura, fato que contribui para maior importância desse curso de extensão. Já para os professores formados, a importância da temática reflete-se na humanização de sua didática. A compreensão de seus alunos do espaço onde vivem e o entendimento das diversas 
realidades sociais possibilitam a construção de um modelo educacional emancipador que foge dos padrões impostos e agrega valor à história de vida do aluno.

Como referido, no último dia de curso, foi realizado um trabalho de campo no qual, após a parte teórica, os participantes puderam vivenciar as nuances da luta pela terra no Brasil. Num primeiro momento, visitamos o acampamento 10 de Maio, do MST, território transitório no processo de luta pela terra. Posteriormente, visitamos o assentamento Emiliano Zapata, também do MST, onde as famílias assentadas estão vivendo do seu trabalho na terra conquistada. As visitas possibilitaram aos cursistas perceberem as diferenças entre os distintos momentos da luta pela/na terra.

A possibilidade de ir a campo e conhecer a realidade de pessoas que vivenciam as problemáticas geradas pela questão agrária auxiliou os cursistas a compreenderem mais desta realidade e a quebrar preconceitos existentes em relação aos movimentos sociais de luta pela terra.

\section{Considerações finais}

A formação docente voltada à Educação do Campo em Uberlândia ainda se encontra defasada. Além dos 15 assentamentos rurais e dos vários acampamentos no município, há um grandenúmerodeagricultoresfamiliaresalocados em distritos e vilas. Esta população do campo encontra enorme dificuldade para ter acesso a uma educação que contemple a sua realidade.

Neste sentido consideramos que há a necessidade contínua de promover atividades e cursos que auxiliem a sanar esta problemática. A missão de levar a Educação do Campo adiante deve partir não só dos professores, por meio de sua formação continuada, mas também do Estado, com a adequação dos currículos para as escolas do campo e o incentivo para a realização de cursos como o relatado.

Pode-se concluir que o curso de extensão alcançou seus objetivos de contribuir com a formação profissional dos participantes e fomentar o debate no interior da Universidade.

\section{Referências}

BRANDÃO, C. R. A educação popular na escola cidadã. Petrópolis, RJ: Vozes, 2002.

BRASIL. Lei de Diretrizes e Bases da Educação Nacional. Lei no 9.394, de 20 de dezembro de 1996. Estabelece as diretrizes e bases da educação nacional. Brasília, DF, 1996.

. Decreto 7.352, de 4 de novembro de 2010. Dispõe sobre a política de educação do campo e o Programa Nacional de Educação na Reforma Agrária - PRONERA. Brasília, DF, 2010.

. Ministério da Educação e do Desporto, Secretaria de Educação Fundamental. Referencial curricular nacional para a educação infantil: Conhecimento de mundo. Brasília, DF: MEC/SEF, 1998.

CALDART, R. S. (Org.) Dicionário da educação do campo. Rio de Janeiro: Escola Politécnica de Saúde Joaquim Venâncio; São Paulo: Expressão Popular, 2012.

DATALUTA-MG. Relatório 2010. Uberlândia: Laboratório de Geografia Agrária, 2011. Disponível em: <http://www.lagea.ig.ufu.br/relatoriosdatalutaminas.html>. Acesso em: 10 nov. 2013.

DELGADO, G. C. Capital financeiro e agricultura no Brasil: 1965-1985. São Paulo: Ícone; Campinas: Editora da Unicamp, 1985. 
FERNANDES, B. M. A formação do MST no Brasil. Petrópolis: Vozes, 2000.

FREIRE, P. Pedagogia do oprimido, 14. ed. Rio de Janeiro: Paz e Terra, 1983.

GRZYBOWSKI, C. Caminhos e descaminhos dos movimentos sociais no campo. 2. ed. Rio de Janeiro: Vozes, 1987.

LEITE, R.; CHELOTTI, M. C. Geografia da educação do campo no Triângulo Mineiro. Revista HISTEDBR, Campinas, n. 50, p. 226-237, maio 2013.

LEITE, S. C. Escola Rural: urbanização e políticas educacionais. 2. ed. São Paulo: Cortez, 2002.

MEURER, A. C.; DE DAVID, C. Educação no campo e escola itinerante do MST: articulação do projeto político-pedagógico com o contexto sócio-educacional. Educação: Revista do Centro de Educação, Santa Maria, v. 33, n. 1, p. 45-56, jan./abr. 2008.

MÉZÁROS, I. A educação para além do capital. Tradução de Isa Tavares. São Paulo: Boitempo, 2008.

MORIGI, V. Escola do MST: uma utopia em construção. Porto Alegre: Mediação, 2003.

OLIVEIRA, A. U. A geografia das lutas no campo. 13. ed. São Paulo: Contexto, 2005.

PESSÔA, V. L. S. Meio técnico-científico-informacional e modernização da agricultura: uma reflexão sobre as transformações no cerrado mineiro. In: MARAFON, G. J.; RUA, J.;

PULH, R. I.; MEURER, A. C. Um estudo sobre a prática de educação popular da escola itinerante do MST e suas contribuições para qualificação do saber acadêmico nas licenciaturas. Disponível em: <http://www.ufsm.br/gpforma/1senafe/bibliocon/umestudo.rtf>. Acesso em: 26 jun. 2013.

RIBEIRO, M. A. (Org.). Abordagens teórico-metodológicas em geografia agrária. Rio de Janeiro: Editora da UERJ, 2007.

SILVA, J. G. da. A nova dinâmica da agricultura brasileira. Campinas: Editora da Unicamp, 1996.

VENDRAMINI, C. R. A escola diante do multifacetado espaço rural. Perspectiva: Revista do Centro de Ciências da Educação, Florianópolis, v. 21, n.1, p. 145-166, jan./jun. 2004.

WERTHEN, J. BORDEVANE, J. D. (Org.) Educação rural no Terceiro Mundo: experiências e novas alternativas. Tradução de Paulo Roberto Kraner e Lúcia Teresa Lessa Carregal. 2. ed. Rio de Janeiro: Paz e Terra, 1985.

Submetido em 14 de fevereiro de 2014.

Aprovado em 7 de março de 2014. 